\title{
ANALISIS FAKTOR-FAKTOR YANG BERPENGARUH TERHADAP KINERJA BENDAHARA SERTA DAMPAKNYA TERHADAP PENYERAPAN ANGGARAN ORGANISASI PERANGKAT DAERAH PADA PEMERINTAH KABUPATEN TABANAN
}

\author{
Ni Wayan Sukerni ${ }^{1)}$ \\ I.A.A.N. Marhaeni' ${ }^{2)}$ \\ ${ }^{12}$ Fakultas Ekonomi dan Bisnis Universitas Udayana (unud), Bali, Indonesia \\ Email : adindadantia@gmail.com
}

\begin{abstract}
ABSTRAK
Diberlakukannya otonomi daerah memberikan peluang Pemerintah Daerah dalam menyelenggarakan pemerintahan sesuai potensi yang dimiliki daerah. Hasil evaluasi Laporan Akuntabilitas Kinerja Instansi Pemerintah Kabupaten Tabanan dengan predikat penilaian B dan Wajar Tanpa Pengecualian. Penelitian ini bertujuan untuk menganalisis faktor-faktor yang Berpengaruh Terhadap Kinerja Bendahara Serta Dampaknya Terhadap Penyerapan Anggaran Organisasi Perangkat Daerah Pada Pemerintah Kabupaten Tabanan. Penelitian menggunakan analisis Structural Equetion Modell (SEM) PLS dan jumlah responden 56 orang. Hasil penelitian empiris merepresentasikan; (i) kelengkapan fasilitas, kualitas sumber daya manusia, kondisi lingkungan kerja, dan karakteristik bendahara berdampak positif dan berpengaruh signifikan terhadap kinerja bendahara, (ii) kelengkapan fasilitas, kualitas sumber daya manusia dan kondisi lingkungan kerja, dan kinerja bendahara berpengaruh secara positif dan signifikan terhadap penyerapan anggaran OPD pada Pemerintah Kabupaten Tabanan namun karakteristik bendahara tidak berpengaruh secara signifikan terhadap penyerapan anggaran, (iii) kelengkapan fasilitas, kualitas sumber daya manusia dan kondisi lingkungan kerja dan karakteristik bendahara berpengaruh secara signifikan terhadap penyerapan anggaran OPD pada Pemerintah Kabupaten Tabanan melalui kinerja bendahara.
\end{abstract}

Kata Kunci: Kinerja, Kualitas SDM, Lingkungan Kerja Dan Penyerapan Anggaran.

\begin{abstract}
The implementation of regional autonomy provides an opportunity for local government in organizing the government according to the potential of the region. The result of evaluation of Performance Accountability Report of Agencies of Tabanan Regency Government with unqualified B and B appraisal grade. This study aims to analyze the factors that Affect Against Performance Treasurer And Its Impact Against The Budget Absorption Organization Of Regional Devices In Tabanan Government. The study used Structural Equetion Modell (SEM) analysis of PLS and the number of respondents was 56 people. Empirical research results represent; (i) facility completeness, quality of human resources, working environment, and characteristic of treasurer have positive impact and significant influence to treasurer's performance, (ii) completeness of facility, human resource quality and working environment condition, and performance of treasurer positively and significantly absorption of OPD budget to Tabanan regency government, but characteristic of treasurer does not significantly influence budget absorption, (iii) completeness of facility, quality of human resources and condition of work environment and treasurer characteristics significantly influence to absorption of OPD budget at Tabanan Government through treasurer performance.
\end{abstract}

Keywords: Performance, Quality of Human Resources, Work Environment and Budget Absorption. 


\section{PENDAHULUAN}

Sesuai dengan pelaksanaan otonomi, setiap daerah dituntut untuk melaksanakan pengelolaan keuangan daerah yang efektif, efisien, dan transfaran sesuai dengan ketentuan yang mengatur. Pengelolaan keuangan yang efektif dilakukan melalui berbagai upaya agar dapat mencapai target yang telah ditentukan. Efisiensi dalam pengelolaan keuangan menandakan bahwa besarnya anggaran yang dikeluarkan sebanding dengan hasil yang telah dicapai dalam suatu kegiatan. Transfaransi mencerminkan bahwa pengelolaan keuangan dapat dipertanggungjawabkan, tidak bertentangan dengan ketentuan yang berlaku, serta adanya keterbukaan.

Setiap akhir tahun anggaran pemerintah daerah memiliki kewajiban untuk menyampaikan laporan keuangan daerah. Laporan keuangan yang disajikan harus sesuai dengan ketentuan yang mengatur terhadap pengelolaan keuangan daerah. Pengelolaan dijalankan berlandaskan Peraturan Pemerintah Nomor 24 Tahun 2015 syarat yang harus terpenuhi yaitu relevan, andal, dapat dibandingkan dan dapat dipahami. Laporan Keuangan Pemerintah Daerah yang disampakan oleh kepala daerah setiap akhir tahun anggaran tersebut, diaudit oleh Badan Pemeriksa Keuangan (BPK). BPK akan mengeluarkan opini sebagai respon dari audit laporan yang disampaikan oleh kepala daerah. Opini yang dikeluarkan oleh Badan Pemeriksa Keuangan (BPK) yaitu; Wajar Tanpa Pengecualian (WTP), Wajar Dengan Pengecualian (WDP), Tidak Wajar (TW) dan menolak memberi opini atau Tidak Memberi Pendapat (TMP), (Undang-Undang Nomor 15 Tahun 2004). 
Tabel 1

Perkembangan Opini BPK-RI terhadap LKPD

Pemerintah Kabupaten Tabanan Tahun 2007-2016

\begin{tabular}{cccl}
\hline No & LKPD Tahun & Opini & \multicolumn{1}{c}{ Keterangan } \\
\hline 1 & 2007 & WDP & Pemeriksaan terhadap SPI, dan kepatuhan \\
2 & 2008 & WDP & terhadap peraturan perundang- \\
3 & 2009 & WDP & undangan/SAP \\
4 & 2010 & WDP & \\
5 & 2011 & WDP & \\
6 & 2012 & TMP & \\
7 & 2013 & WDP & \\
8 & 2014 & WTP & \\
9 & 2015 & WTP & \\
10 & 2016 & WTP & \\
\hline
\end{tabular}

Sumber : BPK-RI LHP LKPD Pemerintah Kabupaten Tabanan 2007-2016

Tabel diatas menunjukkan bahwa BPK pernah mengeluarkan TMP terhadap Laporan Keuangan Pemerintah Kabupaten Tabanan Tahun 2012. Opini TMP artinya kondisi laporan keuangan yang disampaikan saat itu tidak dapat dijelaskan, oleh karena BPK tidak menemukan bukti-bukti yang valid untuk mendukung laporan Keuangan tahun 2012 maka diputuskan untuk memberikan opini disclaimer. Pada Tahun 2013 Kabupaten Tabanan telah mendapatkan opini yang lebih baik dan terakhir pada Tahun 2016 mendapat opini Wajar Tanpa Pengecualian (WTP).

Walaupun mendapat opini WTP namun dalam pemeriksaan yang dilakukan masih terdapat temuan tentang ketidakpatuhan terhadap peraturan yang berlaku, dan masih adanya kesalahan yang bersifat keuangan dan bersifat administratif. BPK juga mengeluarkan rekomendasi yang perlu diperhatikan untuk dilakukan perbaikan oleh pihak-pihak yang terkait dengan pelaksanaan pengelolaan keuangan daerah, khususnya perhatian dari bendahara OPD. 
Ni Wayan Sukerni, I.A.A.N. Marhaeni. Analisis Faktor-Faktor Yang Berpengaruh...

Bendahara Organisasi Perangkat Daerah (OPD) yang memiliki kinerja yang baik merupakan salah satu pendukung terhadap realisasi anggaran pada OPD yang nantinya akan berpengaruh terhadap kinerja laporan keuangan daerah. Realisasi belanja yang dapat dilaksanakan sesuai dengan target yang telah ditentukan akan dapat memberikan dampak pada peningkatan kesejahteraan masyarakat. Peningkatan terhadap kesejahteraan masyarakat merupakan tujuan dari pelaksanaan pembangunan daerah. Mengingat pentingnya kinerja bendahara dalam menata usahakan laporan keuangan daerah, serta dampak realisasi belanja daerah terhadap peningkatan kesejahteraan masyarakat menjadi daya tarik bagi penelitian ini. Hasil uji hubungan variabel-variabel dengan menggunakan performa bendahara sebagai variabel interventing, maka penelitian ini akan menjelaskan kontribusi masing-masing variabel dan kemudian dapat digunakan menjadi acuan untuk melakukan pembenahan dalam pengelolaan keuangan daerah di masa-masa yang akan datang.

Kondisi lingkungan kerja yang nyaman membuat bendahara merasa betah berada di kantor, dan dapat melaksanakan tugasnya dengan tenang tanpa adanya gangguan atau perasaan yang tidak nyaman. Situasi yang tenang dapat meningkatkan ketelitian bendahara dalam malaksanakan tugas sehingga tingkat kesalahan dalam bekerja dapat dihindari. Kusuma, (2013) menyatakan bahwa adanya pengaruh yang signifikan antara lingkungan kerja dengan kinerja karyawan. Lingkungan kerja yang sehat dan kondusif diyakini mampu menjadi alasan karyawan lebih betah berada dalam ruangan dari pada beraktivitas diluar, 
sehingga karyawan tersebut dapat menjalankan tugasnya dengan nyaman dan baik (Aityan, 2011).

Kelengkapan fasilitas merupakan faktor pendukung terhadap kinerja individu. Kinerja individu akan dapat berpengaruh terhadap tujuan organisasi. Kelengkapan fasilitas pendukung seperti fasilitas komunikasi, fasilitas transportasi, dan fasilitas teknologi informasi sangat diperlukan dalam melaksanakan tugas-tugas kantor. Dengan adanya fasilitas komunikasi yang memadai dapat mempercepat informasi dan koordinasi bendahara antar OPD. Fasilitas transportasi yang memadai dapat mempercepat proses pelaksanaan tugas bendahara. Begitu juga kelengkapan fasilitas teknologi dan informasi (SIPKD) dapat membantu bendahara lebih cepat dalam melaksanakan tugas karena sudah dilakukan dengan sistem. Fasilitas kerja merupakan faktor pendukung bagi pencapaian kinerja yang tinggi guna mencapai laba perusahaan yang optimal. Berdasarkan penelitian yang dilakukan oleh Fauzia dkk, (2014) mengenai Pengaruh motivasi, disiplin dan fasilitas terhadap kinerja karyawan asuransi bumi putera 1912 semarang menemukan bahwa variabel motivasi, disiplin dan fasilitas memiliki pengaruh yang signifikan terhadap variabel kinerja.

Kualitas sumber daya manusia yang baik akan dapat meningkatkan kinerja. Salah satu upaya dalam meningkatkan kualitas sumber daya manusia yaitu melalui pendidikan. Pendidikan merupakan suatu upaya yang dilakukan secara sadar dalam meningkatkan daya cipta rasa dan karsa manusia untuk meningkatkan kualitas hidup. Tingkat pendidikan yang dimiliki oleh bendahara menjadi faktor penunjang dalam pencapaian kinerja bendahara, pendidikan yang 
rendah sering kali menjadi batasan kepada bendahara dalam mengintrepetasikan informasi tentang tata kelola keuangan daerah yang baik dan sesuai dengan peraturan. Tingkat kompetensi bendahara berpengaruh terhadap kinerja, serta memberikan dampak pada peningkatan kinerja organisasi. Sesuai dengan penelitian yang dilakukan oleh Wasasih (2014) pendidikan berpengaruh secara signifikan dan positif terhadap kinerja bendahara. Talukder (2011) menyatakan bahwa pendidikan, pelatihan dan kompetensi memberikan kontribusi terhadap peningkatan kinerja.

Karakteristik merupakan sifat karakter yang dimiliki oleh seseorang yang dapat melekat pada individu. Dengan adanya karaktersitik individu yang baik akan dapat meningkatkan kinerja pegawai. Devi Arieni dkk. (2015) menyatakan karakteristik individu yang meliputi variabel sikap, minat, motivasi dan kepatuhan memiliki pengaruh positif dan signifikan terhadap kinerja pegawai di UPT. PSMB-Lembaga Tembakau Jember. Pendapat tentang keragaman gender akan membawa pengaruh yang positif bagi organisasi disampaikan oleh Hurst dkk (1989). Usia sebagai dasar mengukur pengalaman dan kemampuan mengambil resiko (Herrmann dan Datta, 2005).

Pemilihan Pemerintah Kabupaten Tabanan sebagai obyek dalam penelitian ini adalah karena pemerintah kabupaten Tabanan pernah mendapat opini TMP pada Tahun 2012, dan telah melakukan perbaikan-perbaikan dalam laporan keuangan daerah sehingga dari Tahun 2013 sampai Tahun 2016 telah berhasil mendapatkan opini WTP. Opini yang diperoleh atas Laporan Keuangan Pemerintah Kabupaten Tabanan (LKPD) Tahun 2016 WTP dengan catatan artinya 
masih ditemukan ketidak patuhan terhadap peraturan perundangan yang berlaku dalam pelaksanaan pengelolaan keuangan sehingga diperlukan adanya perbaikan. Perbaikan tersebut dituangakan dalam bentuk rekomendasi dan saran terhadap pihak yang terkait dengan penelolaan keuangan daerah.

Realisasi penyerapan anggaran belanja daerah pada masing-masing OPD khususnya belanja yang bersentuhan langsung dengan masyarakat akan dapat meningkatkan pergerakan perputaran perekonomian pada masyarakat. Belanja pemerintah merupakan pendorong utama laju pertumbuhan ekonomi. Pelaksanaan kegiatan yang dilakukan lebih awal dapat memberikan manfaat dan efek stimulus yang besar bagi peningkatan kesejahtern masyarakat. Pelaksanaan kegiatan yang dilakukan pada akhir tahun, yang seharusnya dapat dilaksanakan diawal, akan merugikan masyarakat banyak karena terjadi tertundanya penerimaan manfaat.

Birokrasi merupakan suatu mekanisme yang dapat digunakan menjadi tolok ukur efisiensi pelaksanaan kegiatan dalam pencapaian tujuan, (Eisenstadt, 1959). Penelitian mengenai pengaruh penggunaan anggaran terhadap kinerja anggaran yang dilakukan oleh beberapa peneliti antara lain dengan tingkat penekanan anggaran (Otley 1978; Hansen 2004), partisipasi anggaran (Becker 1962), kesulitan target anggaran (Simons 1988; Dunk 1993), strategi organisasi (Hansen 2004). Selain berperan dalam meningkatkan kualitas hidup masyarakat, Birokrasi juga berperan penting memastikan barang publik tersedia dengan baik (Brousseau, 2010).

Penelitian ini bertujuan untuk 1) menganalisis pengaruh kelengkapan fasilitas, kualitas sumber daya manusia, kondisi lingkungan kerja, dan 
Ni Wayan Sukerni, I.A.A.N. Marhaeni. Analisis Faktor-Faktor Yang Berpengaruh...

karakteristik bendahara terhadap kinerja bendahara pada Pemerintah Kabupaten Tabanan, 2) menganalisis pengaruh kelengkapan fasilitas, kualitas sumber daya manusia, kondisi lingkungan kerja, karakteristik bendahara, dan kinerja bendahara terhadap penyerapan anggaran Organisasi Perangkat Daerah (OPD) pada Pemerintah Kabupaten Tabanan, 3) menganalisis pengaruh tidak langsung kelengkapan fasilitas, kualitas sumber daya manusia, kondisi lingkungan kerja dan karakteristik bendahara terhadap penyerapan anggaran Organisasi Perangkat Daerah (OPD) melalui kinerja bendahara pada Pemerintah Kabupaten Tabanan.

\section{METODE PENELITIAN}

Penelitian ini dilakukan terhadap 56 bendahara Organisasi Perangkat Daerah (OPD) pada Pemerintah Kabupaten Tabanan, penelitian ini dilakukan pada Tahun 2017 terhadap faktor-faktor yang berpengaruh terhadap kinerja bendahara.

Dalam penelitian ini menggunakan 3 variabel yaitu: 1) Variabel bebas (independen) yang terdiri dari kelengkapan fasilitas, kualitas SDM, kondisi lingkungan kerja, dan karakteristik bendahara, 2) variabel terikat (dependen) yaitu kinerja bendahara dan penyerapan anggaran, 3) variabel antara (mediasi) yaitu kinerja bendahara. Definisi operasional dari masing-masing variabel adalah sebagai berikut:

1) Kelengkapan fasilitas (X1), merupakan adanya kelengkapan sarana yang diperlukan dalam melaksanakan tugas-tugas bendahara. Kelengkapan fasilitas yang mendukung dalam melaksanakan tugas anatara lain kelengkapan fasilitas transportasi, fasilitas komunikasi, dan fasilitas teknologi. 
Kelengkapam fasilitas diukur berdasarkan persepsi bendahara terhadap kelengkapan sarana dalam menunjang kegiatan kantor menggunakan skala ordinal.

2) Kualitas sumber daya manusia (X2), yaitu kemampuan seseorang dalam melaksanakan pekerjaan dilihat dari pengetahuan, ketelitian, keterampilan dan kemampuan dalam melaksanakan tugas. Kualitas SDM diukur berdasarkan persepsi bendahara terhadap kemampuannya dalam menyelesaikan tugas yang diemban, menggunakan skala ordinal.

3) Kondisi lingkungan kerja (X3), merupakan situasi tempat kerja yang mencermikan situasi yang kondusif dalam melaksanakan pekerjaan, yaitu kenyamanan, keamanan dan tingkat kebersamaan dalam bekerja. Kondisi lingkungan kerja diukur berdasarkan persepsi bendahara tentang situasi yang dirasakan saat melaksanakan pekerjaan, menggunakan skala ordinal.

4) Karakteristik bendahara (X4), merupakan suatu yang mencirikan suatu responden terkait umur, tingkat pendidikan, dan pengalaman kerja. Skala pengukuran umur menggunakan skala rasio, tingkat pendidikan diukur berdasarkan tahun sukses menggunakan skala rasio, pengalaman kerja diukur berdasarkan lamanya menggeluti pekerjaan sebagai bendahara diukur menggunakan skala rasio.

5) Kinerja bendahara (Y1), merupakan hasil kerja yang telah dilakukan oleh bendahara, diukur dengan ketepatan waktu, tingkat kualitas dan kuantitas kerja yang dihasilkan. Kinerja bendahara diukur berdasarkan persepsi bendahara terhadap hasil pekerjaan menggunakan skala ordinal. 
Ni Wayan Sukerni, I.A.A.N. Marhaeni. Analisis Faktor-Faktor Yang Berpengaruh...

6) Penyerapan anggaran (Y2), merupakan perbandingan anatara realisasi yang dicapai dengan anggaran yang telah ditetapkan berdasarkan persentase diukur menggunakan skala rasio.

Jenis data yang digunakan dalam penelitian ini adalah data kualitatif dan kuantitatif. Sumber data dalam penelitian ini adalah: 1) Data primer, merupakan sekelompok data yang dikumpulkan secara aktual dan diperoleh langsung dari narasumber (first hand information) (Silalahi, 2009). Data primer diperoleh melalui penyebaran quisioner kepada bendahara di lingkungan pemerintah Kabupaten Tabanan, 2) Data sekunder, sekumpulan data yang diperoleh dari tangan kedua maupun pihak lain yang sebelum sudah tersedia (Silalahi, 2009). Tehnik analisis yang digunakan dalam penelitian ini adalah statistik asosiatif, menggunakan Stuctural Equation Model (SEM), PLS.

\section{HASIL DAN PEMBAHASAN}

Deskripsi variabel- variabel dalam penelitian diukur melalui indikatorindikator masing-masing variabel. Variabel dalam penelitian ini terdiri dari variabel kelengkapan fasilitas $\left(\mathrm{X}_{1}\right)$, variabel kualitas sumber daya manusia $\left(\mathrm{X}_{2}\right)$, variabel kondisi lingkungan kerja $\left(\mathrm{X}_{3}\right)$, variabel karakteristik bendahara $\left(\mathrm{X}_{4}\right)$, dan variabel kinerja bendahara $\left(\mathrm{Y}_{1}\right)$. Deskripsi variabel dapat memberikan persepsi responden mengenai pernyataan yang diberikan terhadap variabel yang diteliti dengan menggunakan nilai rerata (mean) dari setiap indikatornya. Selanjutnya rata-rata nilai persepsi responden diartikan dan dimaknai memakai kriteria three-box method (Ferdinand, 2006), antara 1,0 - 2,3 adalah kurang baik, antara 2,4 - 3,7 
adalah sedang/cukup baik, dan antara 3,8 - 5,0 adalah tinggi/sangat baik.

\section{Tabel 2}

Skor, persentase responden, dan rerata skor jawaban responden

\begin{tabular}{|c|c|c|c|c|c|c|c|c|}
\hline \multirow[b]{2}{*}{ Variabel } & \multirow[b]{2}{*}{ Indikator } & \multicolumn{5}{|c|}{ Skor dan persentase responden } & \multirow[b]{2}{*}{ Total } & \multirow[b]{2}{*}{ Rerata } \\
\hline & & 1 & 2 & 3 & 4 & 5 & & \\
\hline \multirow[t]{4}{*}{$\mathrm{X} 1$} & $\mathrm{X} 1,1$ & 0 & 0 & 33.93 & 57.14 & 8.93 & 100.0 & 3.75 \\
\hline & $\mathrm{X} 1,2$ & 0 & 0 & 25.00 & 62.50 & 12.50 & 100.0 & 3.88 \\
\hline & $\mathrm{X} 1,3$ & 0 & 0 & 10.71 & 71.43 & 17.86 & 100.0 & 4.07 \\
\hline & Rerata & 0 & 0 & 23.21 & 63.69 & 13.10 & 100.0 & 3.90 \\
\hline \multirow[t]{5}{*}{$\mathrm{X} 2$} & $\mathrm{X} 2,1$ & 0 & 0 & 3.57 & 82.14 & 14.29 & 100.0 & 4.11 \\
\hline & $\mathrm{X} 2,2$ & 0 & 0 & 3.57 & 75.00 & 21.43 & 100.0 & 4.18 \\
\hline & $\mathrm{X} 23$ & 0 & 0 & 10.71 & 83.93 & 5.36 & 100.0 & 3.95 \\
\hline & $\mathrm{X} 2,4$ & 0 & 0 & 8.93 & 78.57 & 12.50 & 100.0 & 4.04 \\
\hline & Rerata & 0 & 0 & 6.70 & 79.91 & 13.39 & 100.0 & 4.07 \\
\hline \multirow[t]{4}{*}{$\mathrm{X} 3$} & $\mathrm{X} 3,1$ & 0 & 0 & 17.86 & 66.07 & 16.07 & 100.0 & 3.98 \\
\hline & $\mathrm{X} 3,2$ & 0 & 0 & 7.14 & 71.43 & 21.43 & 100.0 & 4.14 \\
\hline & $\mathrm{X} 3,3$ & 0 & 0 & 3.57 & 57.14 & 39.29 & 100.0 & 4.36 \\
\hline & Rerata & 0 & 0 & 9.52 & 64.88 & 25.60 & 100.0 & 4.16 \\
\hline \multirow[t]{4}{*}{ Y1 } & $\mathrm{Y} 1,1$ & 0 & 0 & 10.71 & 76.79 & 12.50 & 100.0 & 4.02 \\
\hline & $\mathrm{Y} 1,2$ & 0 & 0 & 3.57 & 85.71 & 10.71 & 100.0 & 4.07 \\
\hline & $\mathrm{Y} 1,3$ & 0 & 0 & 12.50 & 78.57 & 8.93 & 100.0 & 3.96 \\
\hline & Rerata & 0 & 0 & 8.93 & 80.36 & 10.71 & 100.0 & 4.02 \\
\hline
\end{tabular}

Sumber : Lampiran 2

Penyerapan Anggaran Pendapatan dan Belanja Daerah (APBD) Organisasi Perangkat Daerah (OPD) pada Pemerintah Kabupaten Tabanan Tahun Anggaran 2016 rata-rata mencapai 95,04 persen. Serapan anggaran pada masing-masing OPD pada Pemerintah Kabupaten Tabanan dapat dilihat pada Tabel berikut. 
Tabel 3

Serapan anggaran Organisasi Perangkat Daerah $\left(\mathrm{Y}_{2}\right)$ pada Pemerintah Kabupaten Tabanan Tahun 2016

\begin{tabular}{|c|c|c|c|c|}
\hline NO & OPD & Anggaran & Realisasi & $\begin{array}{c}\text { Serapan } \\
\text { Anggaran (\%) }\end{array}$ \\
\hline 1 & SETDA & $77.808 .159 .100,00$ & $73.204 .846 .040,00$ & 94,08 \\
\hline 2 & SETWAN & $48.400 .288 .460,00$ & $45.821 .209 .562,00$ & 94,67 \\
\hline 3 & BAPPEDA & $12.683 .858 .490,00$ & $11.909 .726 .559,00$ & 93,90 \\
\hline 4 & BKD & $11.932 .938 .000,00$ & $11.128 .393 .705,00$ & 93,26 \\
\hline 5 & INSPEKTORAT & $11.130 .619 .800,00$ & $10.659 .402 .066,00$ & 95,77 \\
\hline 6 & BRSU & $168.370 .452 .546,50$ & $161.841 .530 .429,68$ & 96,12 \\
\hline 7 & BPMD & $8.773 .960 .700,00$ & 8.327.125.642,00 & 94,91 \\
\hline 8 & BPMPD & $6.338 .216 .225,00$ & $5.982 .595 .795,00$ & 94,39 \\
\hline 9 & BADAN KESBANG & $5.263 .188 .300,00$ & $5.011 .670 .700,00$ & 95,22 \\
\hline 10 & BAPELUH & $20.449 .997 .700,00$ & $20.326 .481 .942,00$ & 99,40 \\
\hline \multirow[t]{2}{*}{11} & BADAN PPPA dan & & & \\
\hline & $\mathrm{KB}$ & $9.133 .763 .000,00$ & $8.691 .688 .348,00$ & 95,16 \\
\hline 12 & BLH & $5.719 .227 .100,00$ & $5.299 .254 .405,00$ & 92,66 \\
\hline 13 & BPBD & $7.188 .729 .650,00$ & $6.948 .132 .401,00$ & 96,65 \\
\hline 14 & KKP & $2.564 .873 .000,00$ & 2.391.836.038,00 & 93,25 \\
\hline 15 & KANTOR PERSIP & $3.114 .810 .800,00$ & $2.915 .268 .354,00$ & 93,59 \\
\hline 16 & DISKES & $120.625 .663 .506,00$ & $110.285 .308 .165,10$ & 91,43 \\
\hline 17 & DISBUDPAR & $11.673 .794 .000,00$ & $11.341 .968 .848,00$ & 97,16 \\
\hline \multirow[t]{2}{*}{18} & DISKOP DAN & & & \\
\hline & UMKM & $5.273 .330 .000,00$ & $5.048 .746 .042,00$ & 95,74 \\
\hline 19 & DKP & $24.563 .781 .700,00$ & $23.587 .407 .796,50$ & 96,03 \\
\hline 20 & DPU & $260.742 .686 .000,00$ & $251.320 .021 .375,00$ & 96,39 \\
\hline 21 & DISDIKMUDORA & $785.412 .379 .863,00$ & $649.576 .466 .196,98$ & 82,71 \\
\hline 22 & DISHUTBUN & $11.000 .034 .500,00$ & $10.442 .932 .094,00$ & 94,94 \\
\hline 23 & DINASTAN & $18.126 .273 .000,00$ & $17.632 .533 .219,00$ & 97,28 \\
\hline 24 & DISKANLA & $9.384 .045 .600,00$ & $9.111 .121 .701,00$ & 97,09 \\
\hline 25 & DISNAK & $11.563 .683 .600,00$ & 10.693.944.901,00 & 92,48 \\
\hline 26 & DISPENDA & $27.930 .802 .110,00$ & $25.304 .716 .079,25$ & 90,60 \\
\hline 27 & DINSOS & $9.510 .342 .000,00$ & $9.045 .377 .538,00$ & 95,11 \\
\hline 28 & DISNAKER & $6.402 .304 .000,00$ & $6.142 .865 .642,00$ & 95,95 \\
\hline 29 & DISDUKCAPIL & $6.328 .434 .500,00$ & $6.144 .579 .275,00$ & 97,09 \\
\hline 30 & DISHUBKOMINFO & $22.032 .980 .440,00$ & $20.943 .918 .859,00$ & 95,06 \\
\hline \multirow{2}{*}{31} & DINAS & & & \\
\hline & PERINDUSTRIAN & $8.044 .072 .500,00$ & $7.418 .197 .606,00$ & 92,22 \\
\hline 32 & SATPOL PP & $11.564 .225 .400,00$ & $11.161 .121 .269,00$ & 96,51 \\
\hline 33 & KEC. KEDIRI & $3.904 .058 .000,00$ & $3.763 .561 .033,00$ & 96,40 \\
\hline 34 & KEC. BATURITI & $3.254 .600 .000,00$ & $3.119 .519 .975,00$ & 95,85 \\
\hline 35 & KEC. PENEBEL & $3.982 .030 .000,00$ & $3.772 .999 .596,00$ & 94,75 \\
\hline 36 & KEC. KERAMBITAN & $3.686 .361 .000,00$ & $3.568 .093 .208,00$ & 96,79 \\
\hline 37 & KEC. SELEMADEG & $3.061 .485 .000,00$ & $2.945 .172 .282,00$ & 96,20 \\
\hline 38 & KEC. SELTIM & $2.972 .719 .000,00$ & $2.860 .333 .351,00$ & 96,22 \\
\hline 39 & KEC. SELBAR & 2.794.383.000,00 & $2.665 .941 .801,00$ & 95,40 \\
\hline 40 & KEC. PUPUAN & $3.681 .446 .000,00$ & $3.544 .361 .825,00$ & 96,28 \\
\hline 41 & KEC. TABANAN & $3.125 .120 .400,00$ & $3.036 .575 .901,00$ & 97,17 \\
\hline & KEC. MARGA & $3.403 .399 .000,00$ & $3.263 .055 .788,00$ & 95,88 \\
\hline \multirow[t]{2}{*}{43} & SKPKD & 263.938.914.749,94 & $261.688 .111 .175,00$ & 99,15 \\
\hline & & Realisasi rata-rata & & 95,04 \\
\hline
\end{tabular}


Hal pertama yang dilakukan dalam analisis dengan PLS adalah melakukan penilaian outer dari model atau tahap pengukuran (measurement) realibilitas dan validitas variabel dalam model penelitian. Dua kriteria yang dapat digunakan untuk menguji outer dari model yaitu: validitas convergent dan validitas discriminant. Tahap selanjutnya, uji inner model atau yang sering disebut struktural model. Uji model struktural dijalankan untuk mengetahui hubungan antar variabel, yang ditunjukkan oleh nilai signifikansi dan nilai R-square dari hasil uji. Hal ini selaras dengan tujuan penelitian untuk mengetahui kolerasi antara variabel bebas terhadap variabel terikat.

Analisis yang digunakan untuk mengetahui validitas indikator-indikator yang membentuk konstruk :

\section{1) Validitas Convergent}

Validitas konvergen (Convergent Validity) yang diperoleh dari hasil uji PLS (Partial Least Square) digunakan sebagai indikator untuk membentuk konstruk kelengkapan fasilitas $\left(\mathrm{X}_{1}\right)$ kualitas $\mathrm{SDM}\left(\mathrm{X}_{2}\right)$, kondisi lingkungan kerja $\left(\mathrm{X}_{3}\right)$, karakteristik bendahara $\left(\mathrm{X}_{3}\right)$ dan kinerja bendahara $\left(\mathrm{Y}_{1}\right)$ signifikan dibuktikan dengan hasil uji t-value melebihi 1,96 dan p-value dibawah 0,05. Dengan koefisien keseluruhan indikator yang berada diatas 0,05, maka syarat validitas konvergen model terpenuhi. Hasil estimasi outer loading digunakan sebagai indikator konstruk variabel kelengkapan fasilitas, kondisi lingkungan kerja, kualitas SDM, karakteristik bendahara, dan kinerja bendahara pada Pemerintah Kabupaten Tabanan dapat dilihat pada Tabel berikut. 
Tabel 4

Outer Loading indikator terhadap konstruk kelengkapan fasilitas, kualitas SDM, kondisi lingkungan kerja, karakteristik bendahara, dan kinerja bendahara pada Pemerintah Kabuapten Tabanan

\begin{tabular}{lccrc}
\hline \multicolumn{1}{c}{ Hubungan Antar Variabel } & Loading & Sterr & T statistic & P value \\
\hline X1.1 <- Kelengkapan Fasilitas $\left(\mathrm{X}_{1}\right)$ & 0,748 & 0,114 & 6,552 & 0.000 \\
X1.2 <- Kelengkapan Fasilitas $\left(\mathrm{X}_{1}\right)$ & 0,861 & 0,063 & 13,738 & 0.000 \\
X1.3 <- Kelengkapan Fasilitas $\left(\mathrm{X}_{1}\right)$ & 0,691 & 0,164 & 4,209 & 0.000 \\
X2,1 <- Kualitas SDM $\left(\mathrm{X}_{2}\right)$ & 0,765 & 0,103 & 7,439 & 0.000 \\
X2,2 <- Kualitas SDM $\left(\mathrm{X}_{2}\right)$ & 0,858 & 0,046 & 18,670 & 0.000 \\
X2,3 <- Kualitas SDM $\left(\mathrm{X}_{2}\right)$ & 0,612 & 0,133 & 4,605 & 0.000 \\
X2,4 <- Kualitas SDM $\left(\mathrm{X}_{2}\right)$ & 0,860 & 0,041 & 21,188 & 0.000 \\
X3.1 <- Kondisi Lingkungan Kerja $\left(\mathrm{X}_{3}\right)$ & 0,879 & 0,088 & 9,984 & 0.000 \\
X3.2 <- Kondisi Lingkungan Kerja $\left(\mathrm{X}_{3}\right)$ & 0,926 & 0,041 & 22,747 & 0.000 \\
X3.3 <- Kondisi Lingkungan Kerja $\left(\mathrm{X}_{3}\right)$ & 0,518 & 0,160 & 3,245 & 0.001 \\
X4.1 <- Karakterisik Bendahara $\left(\mathrm{X}_{4}\right)$ & 0,817 & 0,050 & 16,386 & 0.000 \\
X4.3 <- Karakterisik Bendahara $\left(\mathrm{X}_{4}\right)$ & $-0,581$ & $-0,120$ & 4,843 & 0.000 \\
X4.4 <- Karakterisik Bendahara $\left(\mathrm{X}_{4}\right)$ & 0,821 & 0,078 & 10,478 & 0.000 \\
Y1.1 <- Kinerja Bendahara $\left(\mathrm{Y}_{1}\right)$ & 0,821 & 0,060 & 13,621 & 0.000 \\
Y1.2 <- Kinerja Bendahara $\left(\mathrm{Y}_{1}\right)$ & 0,804 & 0,077 & 10,505 & 0.000 \\
Y1.3 <- Kinerja Bendahara $\left(\mathrm{Y}_{1}\right)$ & 0,669 & 0,196 & 3,417 & 0.001 \\
& & & &
\end{tabular}

Sumber : Lampiran 9

\section{2) Validitas Discriminan}

Untuk mengetahui validitas suatu konstruk juga dapat dilihat dari Discriminan Validity $(D V)$. Discriminan Validity yang bagus jika indikatornya memiliki crossloading pada konstruk yang lebih besar dibandingkan dengan konstruk lainnya. Hasil crossloading indikator terhadap konstruk kelengkapan fasilitas, kualitas SDM, kondisi lingkungan kerja, karakteristik bendahara, kinerja bendahara dan penyerapan anggaran OPD pada Pemerintah Kabuapten Tabanan terlihat seperti pada Tabel berikut 
Tabel 5

Average Variance Extracted (AVE), Composite Realiability $(\rho \mathrm{c})$ dan Cronbach Alpha kelengkapan fasilitas $\left(\mathrm{X}_{1}\right)$, kualitas $\mathrm{SDM}\left(\mathrm{X}_{2}\right)$, kondisi lingkungan kerja $\left(\mathrm{X}_{3}\right)$, karakteristik bendahara $\left(\mathrm{X}_{4}\right)$, dan kinerja bendahara $\left(\mathrm{Y}_{1}\right)$ pada Pemerintah Kabuapten Tabanan

\begin{tabular}{lccc}
\hline \multicolumn{1}{c}{ Konstruk } & $\begin{array}{c}\text { Average } \\
\text { Variance } \\
\text { Extracted }\end{array}$ & $\begin{array}{c}\text { Composite } \\
\text { Reliability }\end{array}$ & $\begin{array}{c}\text { Cronbach } \\
\text { Alpha }\end{array}$ \\
\hline Kelengkapan Fasilitas $\left(\mathrm{X}_{1}\right)$ & 0.593 & 0.813 & 0.651 \\
Kualitas SDM $\left(\mathrm{X}_{2}\right)$ & 0.609 & 0.860 & 0.781 \\
Kondisi Lingkungan Kerja $\left(\mathrm{X}_{3}\right)$ & 0.633 & 0.830 & 0.694 \\
Karakteristik Bendahara $\left(\mathrm{X}_{4}\right)$ & 0.560 & 0.458 & -0.013 \\
Kinerja Bendahara $\left(\mathrm{Y}_{1}\right)$ & 0.589 & 0.810 & 0.649 \\
\hline Sumber. & & &
\end{tabular}

Sumber : Lampiran 13

Berdasarkan Tabel diatas dapat diketahui bahwa konstruk kelengkapan fasilitas, kualitas SDM, kondisi lingkungan kerja, dan kinerja bendahara sangat tinggi, dimana discriminant validity yang dimiliki diatas 0,50 . Average Variance Extracted ( $A V E$ ), composit reliability dan cronbach alpha memiliki nilai lebih besar dari 0,60. Variabel karakteristik bendahara nilai Average Variance Extracted ( $A V E)$, composite Reliability dan cronbach alpa kurang dari 0,60. Namun karena X4 bukan berskala likert (data ratio) untuk kriteria Cronbach Alpha, maka X4 dikecualikan.

Secara keseluruhan full Model dari faktor-faktor yang mempengaruhi penyerapan anggaran Organisasi Perangkat Daerah OPD pada Pemerintah Kabupaten Tabanan sesuai hasi olahan data dengan PLS ditampilkan pada Gambar berikut. 


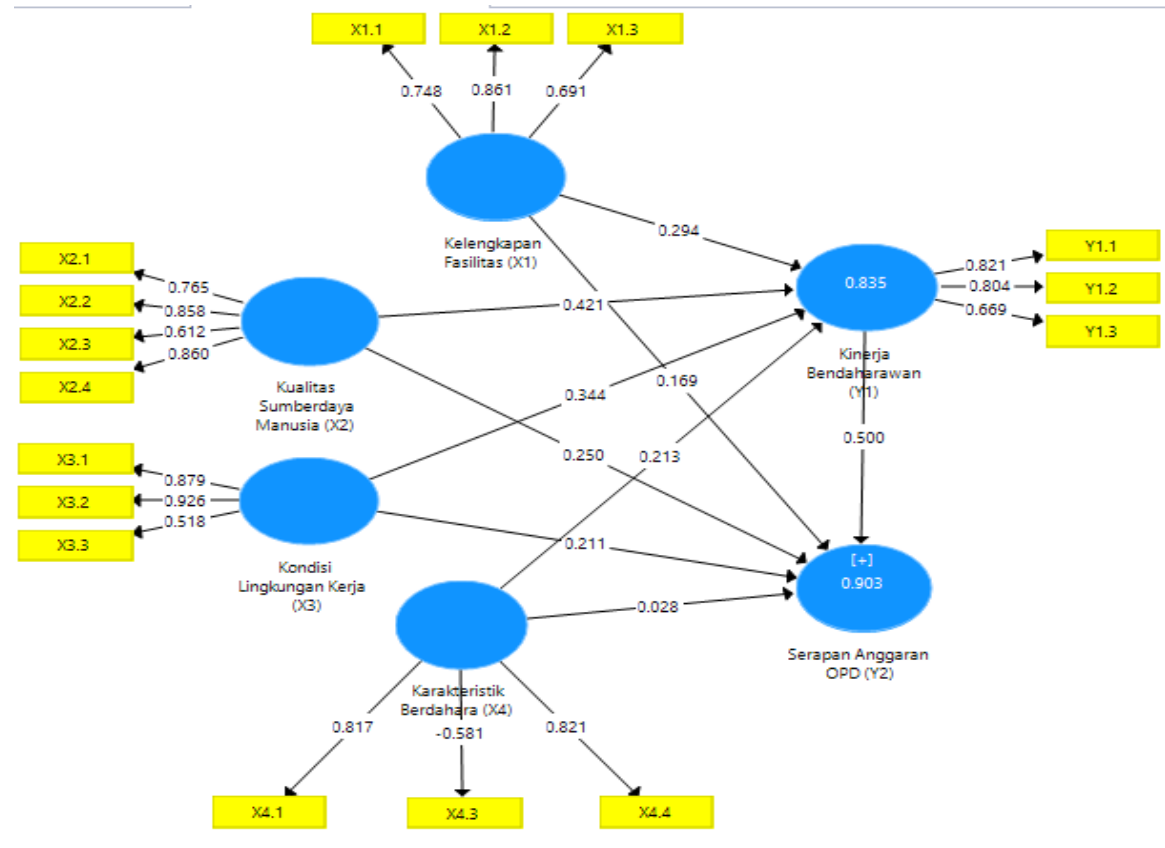

Gambar 1

Full model Faktor-faktor yang mempengaruhi penyerapan anggaran Organisasi Perangkat Daerah pada Pemerintah Kabupaten Tabanan

Berdasarkan hasil dari analisis dan tujuan dari penelitian terdapat dua pengaruh langsung dan satu pengaruh tidak langsung yaitu sebagai berikut :

1) Pengaruh langsung kelengkapan fasilitas, kualitas SDM, kondisi lingkungan

kerja, dan karakteristik bendahara terhadap kinerja bendahara.

Tabel 6

Pengaruh langsung kelengkapan fasilitas, kualitas SDM, kondisi lingkungan kerja, dan karakteristik bendahara terhadap kinerja bendahara

\begin{tabular}{llcccc}
\hline No. & Pengaruh Langsung & $\begin{array}{c}\text { Koefisien Jalur/ } \\
\text { Original } \\
\text { Sample }(\mathrm{O})\end{array}$ & $\begin{array}{c}\text { T Statistic } \\
\text { (O/Sterr) }\end{array}$ & P Value & Ket. \\
\hline 1. $\quad \begin{array}{l}\text { Kelengkapan Fasilitas } \rightarrow \\
\text { Kinerja Bendahara } \\
\text { Kualitas SDM } \rightarrow\end{array}$ & 0.294 & 3.461 & 0.001 & Signifikan \\
Kinerja Bendahara & 0.421 & 4.469 & 0.000 & Signifikan \\
$\begin{array}{l}\text { Kondisi Lingkungan } \\
\text { Kerja } \rightarrow \text { Kinerja } \\
\text { Bendahara } \\
\text { Karakteristik Bendahara } \\
\rightarrow \text { Kinerja Bendahara }\end{array}$ & 0.344 & 4.010 & 0.000 & Signifikan \\
4. & 0.213 & 2.556 & 0.011 & Signifikan \\
\hline
\end{tabular}

Sumber : Lampiran 15 
Dari hasil pengujian hipotesis (inner model) pada Tabel 7 dengan memakai eror 5 persen, t-statistik > 1,96 menunjukkan bahwa variabel kelengkapan fasilitas, kualitas SDM, kondisi lingkungan kerja, dan karakteristik bendahara memiliki pengaruh yang positif dan signifikan terhadap kinerja bendahara.

2) Pengaruh langsung (Result for Inner Model) kelengkapan fasilitas, kualitas SDM, kondisi lingkungan kerja, karakteristik bendahara, dan kinerja bendahara terhadap penyerapan anggaran OPD pada Pemerintah Kabupaten Tabanan.

Tabel 7

Result for Inner Model (pengaruh langsung) kelengkapan fasilitas, kualitas SDM, kondisi lingkungan kerja, karakteristik bendahara, dan kinerja bendahara terhadap penyerapan anggaran OPD pada Pemerintah Kabupaten Tabanan

\begin{tabular}{llcccc}
\hline No & $\quad$ Pengaruh Langsung & $\begin{array}{c}\text { Koefisien } \\
\text { Jalur/Path } \\
\text { coefficients }\end{array}$ & $\begin{array}{c}\text { T Statistic } \\
\text { (O/Sterr })\end{array}$ & P Value & Keterangan \\
\hline 1. $\quad \begin{array}{l}\text { Kelengkapan Fasilitas } \rightarrow \\
\text { Penyerapan Anggaran } \\
\text { Kualitas SDM } \rightarrow \text { Penyerapan } \\
\text { Anggaran }\end{array}$ & 0.169 & 2.280 & 0.023 & Signifikan \\
& $\begin{array}{l}\text { Kondisi Lingkungan Kerja } \rightarrow \\
\text { Penyerapan Anggaran }\end{array}$ & 0.250 & 2.910 & 0.004 & Signifikan \\
3. $\quad \begin{array}{l}\text { Karakteristik Bendahara } \rightarrow \\
\text { Penyerapan Anggaran }\end{array}$ & 0.028 & 0.330 & 0.742 & $\begin{array}{c}\text { Tidak } \\
\text { Signifikan }\end{array}$ \\
$\quad \begin{array}{l}\text { Kinerja Bendahara } \rightarrow \\
\text { Penyerapan Anggaran }\end{array}$ & 0.500 & 3.122 & 0.002 & Signifikan \\
\hline
\end{tabular}

Sumber : Lampiran 15

Dari hasil pengujian hipotesis (inner model) pada Tabel 6 dengan memakai eror 5 persen, t-statistik > 1,96 menunjukkan bahwa variabel kelengkapan fasilitas, kualitas SDM, kondisi lingkungan kerja, dan kinerja bendahara berpengaruh secara positif dan signifikan terhadap penyerapan anggaran OPD pada Pemerintah Kabupaten Tabanan. Variabel karakteristik 
bendahara berpengaruh secara positif namun tidak signifikan terhadap penyerapan angaran OPD pada Pemerintah Kabupaten Tabanan.

3) Pengaruh kelengkapan fasilitas, kualitas SDM, kondisi lingkungan kerja, dan karakteristik bendahara terhadap penyerapan anggaran melalui kinerja bendahara.

Tabel 8

Pengaruh tidak langsung kelengkapan fasilitas, kualitas SDM, kondisi lingkungan kerja, dan karakteristik bendahara terhadap penyerapan anggaran OPD pada Pemerintah Kabupaten Tabanan

\begin{tabular}{|c|c|c|c|c|}
\hline No & Variabel & $\begin{array}{l}\text { Pengaruh langsung } \\
\text { terhadap kinerja } \\
\text { bendahara }\end{array}$ & $\begin{array}{l}\text { Pengaruh } \\
\text { langsung } \\
\text { terhadap } \\
\text { penyerapan } \\
\text { anggaran }\end{array}$ & $\begin{array}{c}\text { Pengaruh tidak langsung } \\
\text { (peranan kinerja } \\
\text { bendahara dalam } \\
\text { memediasi Variabel } \\
\text { independen terhadap } \\
\text { variabel dependen }\end{array}$ \\
\hline 1. & $\begin{array}{l}\text { Kelengkapan } \\
\text { Fasilitas }\end{array}$ & 0.294 ; signifikan & 0.169 ; signifikan & $\begin{array}{l}\text { Signifikan memediasi } \\
\text { secara parsial }\end{array}$ \\
\hline 2. & Kualitas SDM & 0.421 ; signifikan & 0.250 ; signifikan & $\begin{array}{l}\text { Signifikan memediasi } \\
\text { secara parsial }\end{array}$ \\
\hline 3. & $\begin{array}{l}\text { Kondisi } \\
\text { Lingkungan Kerja }\end{array}$ & 0.344 ; signifikan & 0.211 ; signifikan & $\begin{array}{l}\text { Signifikan memediasi } \\
\text { secara parsial }\end{array}$ \\
\hline 4. & $\begin{array}{l}\text { Karakteristik } \\
\text { Bendahara }\end{array}$ & 0.213 ; signifikan & $\begin{array}{l}0.028 ; \text { tidak } \\
\text { signifikan }\end{array}$ & $\begin{array}{l}\text { Signifikan memediasi } \\
\text { penuh }\end{array}$ \\
\hline 5. & Kinerja Bendahara & & 0.500 ; signifikan & - \\
\hline
\end{tabular}

Pengaruh tak langsung diukur dengan cara pengalian antara satu pengaruh langsung dengan pengaruh langsung lainnya melalui variabel antara. Pengaruh tidak langsung akan signifikan bila kedua pengaruh langsungya signifikan, dan bila ada satu dinatara pengaruh langsungnya tidak signifikan menyebabkan pengaruh tidak langsung tidak signifikan. Dalam penelitian ini variabel yang berpengaruh tidak langsung yaitu: pengaruh variabel kelengkapan fasilitas $\left(\mathrm{X}_{1}\right)$ terhadap penyerapan anggaran melalui kinerja bendahara $\left(\mathrm{Y}_{1}\right)$, pengaruh variabel 
kualitas SDM $\left(\mathrm{X}_{2}\right)$ terhadap penyerapan anggaran melalui kinerja bendahara $\left(\mathrm{Y}_{1}\right)$, pengaruh variabel kondisi lingkungan kerja $\left(\mathrm{X}_{3}\right)$ terhadap penyerapan anggaran melalui kinerja bendahara $\left(\mathrm{Y}_{1}\right)$ dan, pengaruh variabel karakteristik bendahara $\left(\mathrm{X}_{3}\right)$ terhadap variabel penyerapan anggaran $\mathrm{OPD}\left(\mathrm{Y}_{2}\right)$ melalui variabel kinerja bendahara $\left(\mathrm{Y}_{1}\right)$ pada Pemerintah Kabupaten Tabanan. Peranan kinerja bendahara sebagai variabel mediasi/perantara variabel kelengkapan fasilitas $\left(\mathrm{X}_{1}\right)$, variabel kualitas $\operatorname{SDM}\left(\mathrm{X}_{2}\right)$, variabel kondisi lingkungan kerja $\left(\mathrm{X}_{3}\right)$ dan variabel karakteristik bendahara $\left(\mathrm{X}_{3}\right)$ terhadap variabel penyerapan anggaran $\mathrm{OPD}\left(\mathrm{Y}_{2}\right)$.

Hasil pengujian hipotesis menunjukkan bahwa secara langsung variabel kelengkapan fasilitas baik terhadap kinerja bendahara, maupun terhadap penyerapan anggaran OPD pada Pemerintah Kabupaten Tabanan adalah signifikan. Peranan kinerja bendahara memediasi secara parsial pengaruh variabel kelengkapan fasilitas terhadap penyerapan anggaran, artinya secara langsung variabel kelengkapan fasilitas berpengaruh terhadap penyerapan anggaran, melalui kinerja bendahara juga berpengaruh secara signifikan. Hal ini berarti semakin lengkap fasilitas yang diberikan kepada bendahara dan semakin baik kinerja bendahara maka penyerapan anggaran juga akan semakin membaik/meningkat. Pengaruh tidak langsung kelengkapan fasilitas terhadap penyerapan anggaran OPD pada Pemerintah Kabupaten Tabanan.

Peranan kinerja bendahara memediasi secara parsial pengaruh variabel kualitas SDM terhadap penyerapan anggaran, artinya secara langsung variabel kualitas SDM berpengaruh terhadap penyerapan anggaran, melalui kinerja bendahara juga berpengaruh secara signifikan. Hal ini berarti semakin bagus 
Ni Wayan Sukerni, I.A.A.N. Marhaeni. Analisis Faktor-Faktor Yang Berpengaruh...

kualitas SDM yang dimiliki oleh bendahara dan semakin baik kinerja bendahara maka penyerapan anggaran juga akan semakin membaik/meningkat. Pengaruh tidak langsung variabel kualitas SDM terhadap penyerapan anggaran OPD pada Pemerintah Kabupaten Tabanan.

Peranan kinerja bendahara memediasi secara parsial pengaruh variabel kondisi lingkungan kerja terhadap penyerapan anggaran, artinya secara langsung variabel kondisi lingkungan kerja berpengaruh terhadap penyerapan anggaran, melalui kinerja bendahara juga berpengaruh secara signifikan. Hal ini berarti semakin bagus variabel kondisi lingkungan kerja yang dirasakan oleh bendahara dan semakin baik kinerja bendahara maka penyerapan anggaran juga akan semakin membaik/meningkat. Pengaruh tidak langsung variabel kualitas SDM terhadap penyerapan anggaran OPD pada Pemerintah Kabupaten Tabanan.

Variabel karakteristik bendahara secara langsung berpengaruh tidak signifikan terhadap penyerapan anggaran OPD pada Pemerintah Kabupaten Tabanan. Peranan kinerja bendahara memediasi secara penuh pengaruh variabel karakteristik bendahara terhadap penyerapan anggaran OPD pada Pemerintah Kabupaten Tabanan, artinya secara langsung berpengruh tidak signifikan terhadap penyerapan anggaran, secara tidak langsung variabel karakteristik bendahara berpengaruh secara signifikan terhadap penyerapan anggaran OPD pada Pemerintah Kabupaten Tabanan. Hal ini berarti sebagus apapun karakteristik yang dimiliki oleh bendahara tidak akan berpengaruh yang berati terhadap penyerapan angaran OPD pada Pemeintah Kabupaten Tabanan, tanpa didukung oleh kinerja bendahara yang baik. Pengaruh tidak langsung variabel karakteristik 
bendahara terhadap penyerapan anggaran OPD pada Pemerintah Kabupaten Tabanan.

Hasil analisis dalam penelitian ini menunjukkan kelengkapan fasilitas, kualitas SDM, kondisi lingkungan kerja dan karakteristik bendahara berpengaruh signifikan terhadap kienerja bendahara sejalan dengan penelitian yang dilakukan oleh Fauzia dkk (2014), menemukan bahwa fasilitas berpengaruh signifikan terhadap kinerja. Warisno, (2009) dalam penelitiannya menunjukkan bahwa secara simultan kualitas sumber daya manusia dan sarana pendukung berpengaruh secara signifikan terhadap kinerja pengelolaan keuangan SKPD. Penelitian yang dilakukan oleh Juita (2013) menemukan bahwa kualitas sumber daya manusia berpengaruh secara signifikan terhadap kinerja SKPD. Berdasarkan penelitian yang dilakukan oleh Kusuma (2013) menemukan Ada pengaruh signifikan Motivasi dan Lingkungan Kerja terhadap Kinerja Karyawan. Malonda dkk. (2014) menyatakan bahwa karakteristik individu, kompensasi dan motivasi secara simultan dan parsial memiliki pengaruh positif dan signifikan terhadap kinerja karyawan pada PT Bank Sulut.

Berdasarkan hasil dari analisis menyatakan bahwa kelengkapan fasilitas, kualitas SDM, kondisi kerja dan kinerja bendahara memiliki pengaruh signifikan terhadap penyerapan anggaran sejalan dengan hasil penelitian yang dilakukan oleh Zarinah dkk. (2016) yang menyatakan kualitas sumber daya manusia berpengaruh positif dan signifikan terhadap penyerapan anggaran. Didukung dengan penelitian yang dilakukan oleh Azkia dkk. (2016), berdasarkan analisisnya menemukan bahwa kualitas SDM dan akuntabilitas publik baik secara simultan maupun parsial 
Ni Wayan Sukerni, I.A.A.N. Marhaeni. Analisis Faktor-Faktor Yang Berpengaruh...

berpengaruh secara positif dan signifikan terhadap kinerja pengelolaan keuangan. Kompetensi sumber daya manusia memiliki pengaruh yang signifikan penyerapan anggaran juga dinyatakan oleh Putri (2014). Lingkungan kerja yang diciptakan oleh karyawan mendorong perusahaan menjadi lebih efektif, sehingga semangat dan gairah kerja semakin tinggi (Noch, 2007).

Berdasarkan hasil analisis karakteristik bendahara tidak berpengaruh secara signifikan terhadap penyerapan anggaran. Namun secara tidak langsung karakteristik bendahara berpengaruh terhadap penyerapan anggaran melalui kinerja bendahara. Artinya dibutuhkan adanya kinerja bendahara yang baik/tinggi agar karakteristik bendahara dapat berpengaruh terhadap peningkatan penyerapan anggaran. Variabel karakteristik bendahara yang dicerminkan dengan usia yang produktif, tingkat pendidikan yang tinggi, dan pengalaman kerja yang baik tidak akan berpengaruh secara signifikan terhadap penyerapan angaran tanpa didukung dengan karakteristik bendahara yang baik. Selain itu penyerapan anggaran tidak hanya ditentukan oleh konerja bendahara saja namun yang memegang peranan lebih penting dalam penyerapan anggaran adalah Pejabat Penatausahaan Keuangan (PPK), dan Pengguna Anggaran (PA). Hasil ini tidak sesuai dengan penelitian yang dilakukan oleh Noviwijaya dan Rohman (2013) menyatakan bahwa keberagaman gender dan usia berpengaruh secara bersama terhadap serapan anggaran.

Mengacu dengan hipotesis, menunjukkan pengaruh tidak langsung kelengkapan fasilitas, kualitas SDM, kondisi lingkungan kerja dan karakteristik bendahara berpengaruh positif dan signifikan terhadap penyerapan anggaran OPD 
pada Pemerintah Kabupaten Tabanan. Hasil penelitian ini sejalan dengan beberapa hasil penelitian yang menyatakan Pengembangan sumber daya manusia atau karyawan berkaitan dengan peningkatan kinerja karyawan itu sendiri. Pernyataan tersebut selaras dengan penelitian Suryantari (2012), dan Widyawati (2008). Lingkungan kerja berpengaruh secara positif dan signifikan terhadap kinerja karyawan (Analisa, 2011). Juliani dan Solihin, (2014) menyatakan bahwa lingkungan birokrasi berpengaruh positif terhadap penyerapan anggaran. Noviwijaya dan Rohman, (2013) menyatakan bahwa keberagaman gender dan usia memiliki pengaruh terhadap penyerapan anggaran. Juga dinyatakan keragaman usia berpengaruh positif terhadap penyerapan anggaran.

\section{SIMPULAN DAN SARAN}

Sesuai dengan hasil penelitian dan pembahasan dalam penelitian ini dapat ditarik kesimpulan :

1 ) Kelengkapan fasilitas, kualitas SDM, kondisi lingkungan kerja dan karakteristik bendahara secara langsung berpengaruh positif dan signifikan terhadap kinerja bendahara pada Pemerintah kabupaten Tabanan. Artinya bahwa semakin baik kelengkapan fasilitas, kualitas SDM kondisi lingkungan kerja dan karakteristik bendahara maka kinerja bendahara juga akan meningkat.

2 ) Kelengkapan fasilitas, kualitas SDM, kondisi lingkungan kerja, dan kinerja bendahara secara langsung berpengaruh positif signifikan terhadap penyerapan anggaran OPD pada Pemerintah Kabupaten Tabanan. Artinya bahwa semakin baik kelengkapan fasilitas, kualitas SDM, kondisi lingkungan 
kerja dan kinerja bendahara maka penyerapan anggaran juga akan meningkat. Karakteristik bendahara berpengaruh secara positif terhadap penyerapan anggaran namun tidak sigifikan. Artinya jika karakteristik bendahara semakin baik tidak akan memberikan pengaruh yang signifikan terhadap penyerapan anggaran.

3 ) Hasil pengujian hipotesis menunjukkan bahwa secara langsung variabel kelengkapan fasilitas baik terhadap kinerja bendahara, maupun terhadap penyerapan anggaran OPD pada Pemerintah Kabupaten Tabanan adalah signifikan. Peranan kinerja bendahara memediasi secara parsial pengaruh variabel kelengkapan fasilitas terhadap penyerapan anggaran, artinya secara langsung variabel kelengkapan fasilitas berpengaruh terhadap penyerapan anggaran, melalui kinerja bendahara juga berpengaruh secara signifikan. Hal ini berarti semakin lengkap fasilitas yang diberikan kepada bendahara dan semakin baik kinerja bendahara maka penyerapan anggaran juga akan semakin membaik/meningkat. Peranan kinerja bendahara memediasi secara parsial pengaruh variabel kualitas SDM terhadap penyerapan anggaran, artinya secara langsung variabel kualitas SDM berpengaruh terhadap penyerapan anggaran, melalui kinerja bendahara juga berpengaruh secara signifikan.

Peranan kinerja bendahara memediasi secara parsial pengaruh variabel kondisi lingkungan kerja terhadap penyerapan anggaran, artinya secara langsung variabel kondisi lingkungan kerja berpengaruh terhadap penyerapan anggaran, melalui kinerja bendahara juga berpengaruh secara signifikan. 
Variabel karakteristik bendahara secara langsung berpengaruh tidak signifikan terhadap penyerapan anggaran OPD pada Pemerintah Kabupaten Tabanan. Peranan kinerja bendahara memediasi secara penuh pengaruh variabel karakteristik bendahara terhadap penyerapan anggaran OPD pada Pemerintah Kabupaten Tabanan, artinya secara langsung berpengruh tidak signifikan terhadap penyerapan anggaran, secara tidak langsung variabel karakteristik bendahara berpengaruh secara signifikan terhadap penyerapan anggaran OPD pada Pemerintah Kabupaten Tabanan.

Sesuai dengan hasil dalam penelitian, pembahasan, dan kesimpulan ada saran-saran yang berhubungan dengan penelitian ini adalah sebagai berikut:

1) Kelengkapan fasilitas yang diberikan kepada bendahara dalam melaksanakan tugas sudah baik, namun untuk kelengkapan fasilitas transfortasi perlu ditingkatkan lagi karena dari persepsi bendahara terhadap kelengkapan fasilitas transfortasi nilai rata-ratanya lebih kecil dari nilai rata-rata kelengkapan fasilitas telekomunikasi, dan kelengkapan fasilitas teknologi.

2) Kualitas sumber daya manusia yang dimiliki oleh bendahara rata-rata sudah baik namun terkait dengan keterampilan yang dimiliki masih perlu ditingkatkan lagi. Salah satunya upaya yang dapat dilakukan yaitu melalui pelatihan/ bimbingan teknis.

3) Persepsi bendahara mengenai kondisi lingkungan kerja sudah baik namun terciptanya suasana yang nyaman perlu ditingkatkan lagi. Kondisi lingkungan yang nyaman salah satunya dilakukan dengan penataan arsif, dan pengaturan sirkulasi udara dalam ruangan kerja. 
4) Terkait dengan karakteristik bendahara sudah menunjukkan nilai rata-rata yang baik, namun dari segi tingkat pendidikan perlu ditingkatkan lagi karena masih banyak bendahara berpendidikan SMA, dan hanya baru 1 orang yang berpendidikan S1. Salah satunya yaitu dengan memberikan tugas belajar. Dalam penunjukkan bendahara oleh kepala OPD agar memperhatikan pengalaman kerja, usia, dan pendidikan dari bendahara.

5) Kinerja bendahara rata-rata sudah baik namun untuk kuantitas kerja yang dihasilkan oleh bendahara perlu ditingkatkan lagi, yaitu dengan pemberian fasilitas transfortasi yang lebih baik, peningkatan kualitas SDM melalui bimbingan teknis, kondisi linngkungan kerja yang lebih nyaman, dan karakteristik dari bendahara terkait dengan jenjang pendidikan yang lebih tinggi.

6) Koordinasi/komunikasi antar unsur yang terkait dengan realisasi penyerapan anggaran perlu ditingkatkan, agar pelaksanaan penyerapan anggaran dapat terlaksana sesuai dengan jadwal yang telah direncanakan.

\section{REFERENSI}

Aityan SK \& Gupta. TKP. 2011. Challenges of Employee Loyalty in Corporate America. Jurnal: Business and Economics, Journal Research Article, accepted version, 2 (2), p:47-54.

Analisa Lucky Wulan 2011. Analisis Pengaruh Motivasi Kerja dan Lingkungan Kerja terhadap Kinerja Karyawan (Studi Kasus pada Dinas Perindustrian dan Perdagangan Kota Semarang). Skripsi. Universitas Diponegoro Semarang.

Azkia, dkk. 2016. Pengaruh Kualitas Sumber Daya Manusia dan Akuntabilitas Publik terhadap Kinerja Pengelolaan Keuangan di Lingkungan Universitas Islam Negeri Ar-Raniry Banda Aceh. Jurnal Akuntansi Pascasarjana Universitas Syah Kuala Vol. 5 No.4, November 2016.

Becker, S. \& D. Green. 1962. Budgeting and Employee Behavior. The Journal of Business, 35 (4), 392-402. 
Brousseau, E., Y. Schemeil, and J. Sgard. 2010. Bargaining on Law and Bureaucracies: A Constitutional Theory of Development. Journal of Comparative Economics, 38 (3), p:253-266.

Dunk, A. S. 1993. The Effect of Budget Emphasis and Information Asymmetry on the Relation between Budgetary Participation and Slack. The Accounting Review, 68 (2), p:400-410.

Eisenstadt, S. N. 1959. Bureaucracy, Bureaucra-tization, and Debureaucratization. Administrative Science Quarterly, 4 (3), p:302-320.

Fauzia Erinda dkk (2014) Pengaruh Motivasi, Disiplin dan Fasilitas terhadap Kinerja Karyawan Asuransi Bumi Putera 1912 Semarang. Diponegoro Journal of Social and Politic (2014), Hal. 1-10, http://ejournal1.undip.ac.id/index.php/.

Hansen, S. C. \& W. A. Van der Stede. 2004. Multiple Facets of Budgeting: An Exploratory Analysis. Management Accounting Research,15 (4), p:415-439.

Herrmann, P. \& Datta, D. 2005 Relationship between Top Management Team characteristic and Internasional Diversification An empirical investigation. British journal of Management, 16 (1), p:69-78.

Hurst, D.K., J.C., \& White, R.E 1989. Top Management Teams and Organizational Renewal'. Strategic Management Journal,10 (51), p:87-105.

Juita Suci Derma 2013 Pengaruh Kualitas Sumber Daya Manusia Komitmen dan Komunikasi Organisasi terhadap Kinerja Satuan Kerja Perangkat Daerah (SKPD) studi empiris pada SKPD kota Padang. skripsi. Universitas Negeri Padang.

Juliani Dian \& Sholihin Mahfud(2014) Pengaruh Faktor-faktor Kontekstual terhadap Persepsian Penyerapan Anggaran terkait Pengadaan Barang dan Jasa. Jurnal Akuntansi dan Keuangan Indonesia Universitas Gadjah Mada vol. 11no.2, desember 2014.

Kusuma Arta Adi 2013. Pengaruh Motivasi dan Lingkungan Kerja Terhadap Kinerja Karyawan Hotel Muria Semarang. Tesis. Universitas Negeri Semarang.

Malonda Wibie Ch. dkk (2014) Karakteristik Individu, Kompensasi dan Motivasi Karyawan serta Pengaruhnya terhadap Kinerja Karyawan PT Bank Sulut Tbk. Tesis. Universitas Sam Ratulangi Manado Jurnal Emba Vol.2 No.2 Juni 2014, Hal. 1460-1470.

Noch, M.Y. 2007. Pengaruh Kemampuan Kerja, Ligkungan kerja dan Motivasi kerja Terhadap Kinerja Pegawai pada Kantor Balai Pengkajian Teknologi Pertanian/BPTP Papua. Jurnal Ilmu Manajemen. Vol 6, No 3. Hal 62-75

Noviwijaya Amdi \& Rohman Abdul. 2013 Pengaruh Keragaman Gender dan Usia Pejabat Perbendaharaan terhadap Penyerapan Anggaran Satuan kerja 
Lingkup Pembayaran KPPN Semarang I. Diponegoro Journal of Accounting. Vol. 2 Nomor 3 Tahun 2013 hal 1.

Otley, D. T. 1978. Budget Use and Managerial Performance. Journal of Accounting Research, 16 (1), p:122-149

Putri Carlin Tasya 2014. Analisis Faktor-faktor yang Mempengaruhi Penyerapan Anggaran pada Satuan Kerja Perangkat Daerah di Pemerintah Provinsi Bengkulu. Skripsi. Universitas Bengkulu.

Silalahi, Ulber. 2009. Metode Penelitian Sosial. Bandung : PT. Rafika Aditama.

Simons, R. 1988. Analysis of the Organizational Characteristics Related to Tight Budget Goals. Contemporary Accounting Research, 5 (1), p:267-283.

Suryantari, E.P. 2012. Pengaruh Kompensasi, Pelatihan, Kepemimpinan, Lingkungan Kerja dan Motivasi Pada Kinerja Pengelolaan Anggaran Belanja Universitas Udayana. Tesis. Denpasar: Universitas Udayana

Mominul Haque Talukder. Strategic Job Analysis and Competency Modeling in HRM: Lessons from Manufacturing Firms in Bangladesh. Journal of Economics and Behavioral Studies. Vol. 3, 2011. (ISSN: 2220-6140).

Warisno. 2009. Faktor-Faktor yang Mempengaruhi Kinerja Pengelolaan Keuangan Satuan Kerja Perangkat Daerah (SKPD) di Lingkungan Pemerintah Propinsi Jambi. Tesis tidak diterbitkan. Sekolah Pascasarjana Universitas Sumatera Utara : Medan.

Wasasih Ni Made dkk. 2016 Pengaruh Pendidikan dan Kinerja Bendahara dengan Pelatihan dan Motivasi sebagai Pemoderasi E-Jurnal Ekonomi dan Bisnis Universitas Udayana 5 (2), p:359-386.

Widyawati. 2008. Analisis Pengaruh Kompensasi, Pelatihan, Kepemimpinan dan Lingkungan Kerja Terhadap Kinerja Pengelolaan Anggaran di Balai Besar Pengawasan Obat dan Makanan Denpasar. (Tesis). Denpasar: Universitas Udayana.

Zarinah Monik dkk. (2016) Pengaruh Perencanaan Anggaran dan Kualitas Sumber Daya Manusia terhadap Tingkat Penyerapan Anggaran Satuan Kerja Perangkat Daerah di Kabupaten Aceh Utara. Jurnal Magister Akuntansi Pascasarjana Universitas Syah Kuala volume 5. No 1 Pebruari 2016. 